The published version of this article can be found on Nephron

(https://www.karger.com/Journal/OnlineFirst/223854).

\title{
Diagnostic Accuracy of Frailty Screening Methods in Advanced Chronic Kidney Disease
}

Short Title: Frailty Screening in Chronic Kidney Disease

Andrew C. Nixon $\mathrm{MBChB}^{1-3}$, Theodoros M. Bampouras $\mathrm{PhD}^{4}$, Neil Pendleton $\mathrm{MBChB}^{5}$, Sandip Mitra $\mathrm{MD}^{6,7}$, Ajay P. Dhaygude $\mathrm{MD}^{1}$

${ }^{1}$ Department of Renal Medicine, Lancashire Teaching Hospitals NHS Foundation Trust, Preston, United Kingdom, ${ }^{2}$ Centre for Health Research and Innovation, National Institute of Health Research Lancashire Clinical Research Facility, Lancashire Teaching Hospitals NHS Foundation Trust, Preston, United Kingdom, ${ }^{3}$ Division of Cardiovascular Sciences, University of Manchester, Manchester, United Kingdom, ${ }^{4}$ Active Ageing Research Group, University of Cumbria, Lancaster, United Kingdom, ${ }^{5}$ Division of Neuroscience and Experimental Psychology, University of Manchester, Manchester, United Kingdom, ${ }^{6}$ Manchester Academy of Health Sciences Centre, University of Manchester, Manchester, United Kingdom, ${ }^{7}$ Devices for Dignity, National Institute of Health Research MedTech \& In-vitro Diagnostics Cooperative, United Kingdom 
Corresponding Author: Dr Andrew C. Nixon, Department of Renal Medicine, Lancashire Teaching Hospitals NHS Foundation Trust, Royal Preston Hospital, Sharoe Green Lane, Preston, PR2 9HT, UK. Phone 0044-1772523748; e-mail: andrew.nixon@Ithtr.nhs.uk

Keywords: Frailty; Geriatric Nephrology; Chronic Kidney Disease; End Stage Kidney Disease; Haemodialysis.

\section{Abstract}

Background/Aims: Frail patients with chronic kidney disease (CKD) have an increased hospitalisation and mortality rate. However, many popular frailty screening methods have not been validated in patients with CKD. This study evaluates the diagnostic accuracy of several frailty screening methods in patients with CKD G4-5 and those established on haemodialysis (G5D).

Methods: Ninety participants with CKD G4-5D were recruited from Nephrology Outpatient Clinics and two Haemodialysis Units between December 2016 and December 2017. Frailty was diagnosed using the Fried Frailty Phenotype. The following frailty screening tests were evaluated: Clinical Frailty Scale, PRISMA-7, CKD Frailty Index, CKD FI-LAB, walking speed, hand grip strength and Short Physical Performance Battery.

Results: The mean age of participants was 69 years (SD \pm 13 ). A third of participants were dialysis dependent. Nineteen (21\%) patients were categorised as frail, 42 (47\%) as pre-frail and $29(32 \%)$ as robust. Overall, walking speed was the most discriminative measure (AUC 0.97 [95\% confidence interval $[\mathrm{Cl}]: 0.93$ to 1.00 ], sensitivity 0.84 [95\% $\mathrm{Cl}: 0.62$ to 0.94 ], 
specificity 0.96 [ $95 \% \mathrm{Cl}: 0.88$ to 0.99$])$. The Clinical Frailty Scale had the best performance of the non-physical assessments (AUC 0.90 [95\% Cl: 0.84 to 0.97 ], sensitivity 0.79 [95\% $\mathrm{Cl}: 0.57$ to 0.91 ], specificity 0.87 [95\% $\mathrm{Cl}: 0.78$ to 0.93$])$.

Conclusions: Walking speed can be used to accurately screen for frailty in CKD populations. If it is not practical to perform a physical assessment to screen for frailty, the Clinical Frailty Scale is an accurate alternative. 


\section{List of Abbreviations}

AUC

$\mathrm{Cl}$

CKD

CKD G4

CKD G5

CKD G5D

$\mathrm{FI}$

IQR

ROC

SCREEN I

SD

SPPB
Area Under the Curve

Confidence Interval

Chronic kidney disease

Chronic kidney disease stage 4

Chronic kidney disease stage 5

Dialysis-dependent chronic kidney disease

Frailty Index

Interquartile range

Receiver Operator Characteristic

Seniors in the Community: Risk Evaluation for Eating and Nutrition

Index

Standard deviation

Short Physical Performance Battery 


\section{INTRODUCTION}

Frailty is an especially problematic condition associated with ageing, though it is not universally experienced by all elderly individuals [1]. It is a state of increased vulnerability such that individuals who may otherwise live independently require additional care and support when exposed to even minor physical stressors, for example a simple infection or fall [1]. It is the result of progressive and sustained deterioration of numerous physiological processes, which when accumulated are associated with adverse health outcomes [1]. Many of the pathophysiological processes inherent to chronic kidney disease (CKD) appear to propagate the trajectory from robustness to frailty [2]. The prevalence of frailty increases with worsening kidney function, with a report categorising as many as two thirds of dialysisdependent CKD patients as frail $[3,4]$. Importantly, frail patients with CKD have worse outcomes than those that are robust with CKD, including an increased falls, hospitalisation and mortality rate [3-12].

An international consensus group has advised that frailty screening should be routinely performed in older adults so that targeted management strategies can be offered [13]. Arguably, this is especially important in those with chronic conditions, such as CKD, given the associated predisposition to frailty. Several concepts of frailty have been proposed with varying degrees of physical, psychological and social components. The two most popular concepts are the Fried Physical Frailty Phenotype and the deficit accumulation model, also known as the Frailty Index (FI) $[14,15]$. Though both have their individual merits, the Frailty Phenotype has a more robust evidence base in terms of predicting outcomes in CKD cohorts [3]. The Frailty Phenotype is a time-consuming evaluation involving a combination of 
questionnaires and physical assessments (Table 1) [14]. It is therefore not practical to perform this assessment routinely within nephrology outpatient services. Unfortunately, there is poor agreement between nephrologist-perceived frailty and this suggested diagnostic criteria for physical frailty [16]. Hence, there is a need for an efficient, sensitive and discriminative outpatient screening method in the CKD population that identifies at risk individuals likely to have frailty, as defined by an acknowledged operationalised definition of the construct of frailty. Several frailty screening methods have been validated in the general older population [17]. However, many popular frailty screening methods have not been studied in CKD patients. This study evaluates the diagnostic accuracy of several proposed frailty screening methods in patients with CKD stage 4 and 5 (G4-5) and those established on haemodialysis (G5D), using the Frailty Phenotype as the reference standard. 


\section{METHODS}

\section{Study Design and Participant Selection}

A convenience series of participants was recruited from Lancashire Teaching Hospitals NHS Foundation Trust between December 2016 and December 2017 from nephrology outpatient clinics and two Haemodialysis Units. Though there are distinctions between patients that are pre-dialysis and dialysis-dependent, the drivers of frailty are similar and the clinical expression of frailty is comparable [18]. Therefore, patients $\geq 18$ years old with CKD G4-5 and CKD G5D were eligible for participation in the study. Patients who had a lower limb amputation, metastatic carcinoma, unstable angina or who had a been diagnosed, in the preceding 3 months, with a myocardial infarction, transient ischaemic attack or stroke were excluded from the study. Patients who did not have sufficient understanding of the English language to complete study questionnaires were also excluded. Ethical approval was obtained from the NHS Health Research Authority (IRAS Project ID 216379). Formal written informed consent was obtained for all participants.

\section{Data Collection and Analyses}

Prior to the assessment of index tests, baseline demographic and clinical characteristics data was collected from medical records and during participant interview/assessment. All participants had a Charlson Comorbidity Index score calculated and a Karnofsky Performance Status Scale assessment performed. Participants also completed the Mini- 
Mental State Examination and the Seniors in the Community: Risk Evaluation for Eating and Nutrition Index (SCREEN I) $[19,20]$.

The following frailty screening methods were assessed: Clinical Frailty Scale, PRISMA-7 questionnaire, CKD Frailty Index (FI), CKD FI-LAB, walking speed, hand grip strength and the Short Physical Performance Battery (SPPB) [15,21-24]. The Clinical Frailty Scale is a frailty assessment tool that provides 9 descriptors of levels of fitness/frailty (Figure 1) [15]. It relies upon a health professional's assessment of an individual's frailty status using the descriptors as guidance. A score of ' 4 ' defines individuals as 'vulnerable', whereas a score of ' 5 ' considers individuals to be 'mildly frail'. The Clinical Frailty Scale was assessed by a doctor who had access to participant clinical records prior to performing the assessment [15]. The British Geriatrics Society has recommended the PRISMA-7 as a frailty screening tool, with a cut-off of $\geq 3$ used to identify vulnerable individuals (Table 2 ) [21,25]. Participants were asked the questions within the PRISMA-7 questionnaire by a member of the research team. Published recommendations were used to construct a CKD FI and CKD FI-LAB (Supplementary Table 1 and 2, respectively) $[22,23,26]$. Although the FI was not originally intended to be dichotomised, a cut-off of $>0.21$ has been suggested in the literature [26]. At least $70 \%$ of variables were required to generate a CKD FI-LAB score [23].

Hand grip strength (Takei 5101 GRIP-D dynamometer, Takei Scientific Inst. Co. Ltd., Niigata, Japan) was assessed in the seated position with the elbow positioned at 90 degrees, supported by the arm of a chair, and the dynamometer supported by the assessor. Both arms were examined with the highest score from three efforts from each side being used for analysis [27]. The body mass index and gender stratified hand grip strength cut-offs 
proposed by the Fried Frailty Phenotype were used to identify frailty [14]. Lauretani et al's proposed cut-offs of $<30 \mathrm{~kg}$ for men and $<20 \mathrm{~kg}$ for women for the diagnosis of sarcopenia were also assessed [28]. Walking speed was assessed by asking participants to walk 15 feet $(4.57 \mathrm{~m})$ at their normal walking pace on two occasions. Participants were advised to use their walking aid, if they normally used one. Infrared timing gates (Brower Timing System 2012, Brower Timing Systems, Draper, UT, USA) were used to record walking time. The fastest of two trials was used for analysis. Participants physically unable to complete the assessment were assigned the slowest time within the cohort. The height and gender stratified walking speed cut-offs suggested by the Fried Frailty Phenotype were used to identify frailty [14]. Lauretani et al's proposed cut-off of $\leq 0.8$ metres/second for the diagnosis of sarcopenia was also assessed [28]. Finally, the SPPB, a composite measure of lower extremity function, was performed $[24,29]$. In addition to an assessment of walking speed described above, it includes an assessment of balance and time to complete 5 chair stands [24,29]. A cut-off of 9 has been suggested to identify at risk individuals [29].

The Frailty Phenotype was used as the reference standard for all screening tests [14]. It was assessed as originally described by Fried et al, including assessments of unintentional weight loss, weakness (handgrip strength), self-perceived exhaustion, slowness (walking speed) and physical activity (Table 1) [14]. Frailty was diagnosed if 3 or more frailty criteria were present. Pre-frailty was defined as the presence of 1 or 2 frailty criteria. The Frailty Phenotype assessment was performed at the same study visit as, and immediately following, index test assessments (except in the case of hand grip strength, walking speed and SPPB assessments, which were performed concurrently). 
Given that hand grip strength and walking speed were also components of the Frailty Phenotype, a modified version of the Frailty Phenotype was created and used as the reference standard in a sensitivity analysis. Participants completed the RAND 36-Item Health Survey 1.0 and were assigned 2 points if they scored $<75$ in the physical function domain. As described by Johansen et al, this score replaced the measures of weakness and slowness described in the original Frailty Phenotype [4]. Unintentional weight loss, self-perceived exhaustion and physical activity were assessed as described by Fried et al (Table 1) [14].

\section{Statistical Analysis}

All statistical analyses were performed on IBM SPSS Statistics Software (version 22, IBM Corp) or StatsDirect Statistical Software (version 3.0.167, 28/01/2016). Descriptive statistics were used to summarise demographic data and clinical characteristics. Differences in baseline demographic and clinical characteristic data between non-frail and frail participants was assessed using the Independent T test, Mann Whitney $U$ test, Chi-squared test and Fishers Exact test depending upon the type and distribution of the data. Considering type 1 errors associated with multiple comparisons, a Holm-Bonferroni Sequential Correction was applied when comparing baseline demographics and clinical characteristics between groups [30,31]. The Chi-squared test for trend was used to assess the differences between the proportion of participants categorised as robust, pre-frail and frail by CKD stage. The correlation between index tests and the Frailty Phenotype was assessed using Spearman's Correlation. Receiver Operator Characteristic (ROC) analyses were performed for the screening tests to establish the Area Under the Curve (AUC) and review the sensitivity and specificity of test cut-offs. Additional tests of diagnostic accuracy 
included: positive predictive value, negative predictive value, positive likelihood ratio and negative likelihood ratio. A two-tailed $p$ value $<0.05$ was considered statistically significant.

\section{Sample Size}

The sample size calculation was primarily based on obtaining a 95\% confidence interval width of no more than 0.17 for the Spearman correlation between the Clinical Frailty Scale and the Frailty Phenotype scores, assuming a true correlation of 0.8 . This gave a minimum sample size of 90, using the two-stage approximation suggested by Bonnett and Wright [32]. A sample size of 90 (with an assumed 20 frail and 70 non-frail individuals, defined by the Frailty Phenotype) also enables an estimation of the AUC from a ROC curve analysis to within \pm 0.1 with $95 \%$ confidence, assuming a true AUC of 0.9.[33] 


\section{RESULTS}

A total of 90 participants completed all assessments (Figure 2). The mean age of participants was 69 years ( $S D \pm 13$ ) with an equal number of male and female participants. Most participants were white British ( $n=87,97 \%)$. A third of participants were dialysis dependent. Nineteen (21\%) patients were categorised as frail, 42 (47\%) as pre-frail and 29 (32\%) as robust. Study visits were approximately 90 minutes in duration. Breaks were allowed as needed, though participants did not report suffering any fatigue during visits. No adverse events occurred during assessments.

\section{Frailty Associations}

Table 3 demonstrates the demographics and clinical characteristics of non-frail (including robust and pre-frail) and frail participants. Frail participants had a lower Karnofsky score (60 vs. $80, p<0.001$ ) than non-frail participants. Notably, there was no statistically significant difference in age and Charlson Comorbidity Index between frail and non-frail participants (73 years vs. 68 years [ $p=1.00]$ and 4 vs. $3[p=1.00]$, respectively). There was a higher proportion of dialysis-dependent participants categorised as frail when participants were sub-classified as robust, pre-frail and frail and by CKD stage (CKD G4 11\%, CKD G5 20\%, CKD G5D 33\%, p=0.01, Figure 3). 


\section{Frailty Screening Methods}

Table 4 demonstrates the diagnostic accuracy of the frailty screening methods. Overall, walking speed had the highest AUC value (0.97 [95\% confidence interval [CI]: 0.93 to 1.00]). The Frailty Phenotype walking speed criterion cut-off was most discriminative with a sensitivity of 0.84 ( $95 \% \mathrm{Cl}: 0.62$ to 0.94$)$ and specificity of 0.96 ( $95 \% \mathrm{Cl}: 0.88$ to 0.99$)$. This was associated with a high positive predictive value and negative predictive value $(0.84$ [ $95 \% \mathrm{Cl}: 0.62$ to 0.94$]$ and 0.96 [95\% $\mathrm{Cl}: 0.88$ to 0.99 ], respectively). Of the non-physical assessments, the Clinical Frailty Scale assessment had the highest AUC value $(0.90[95 \% \mathrm{Cl}$ : 0.84 to 0.97$])$. It had good sensitivity and specificity when using a cut-off of $\geq 5(0.79[95 \% \mathrm{Cl}$ : 0.57 to 0.91 ] and 0.87 [95\% $\mathrm{Cl}: 0.78$ to 0.93 ], respectively). The negative predictive value was excellent (0.94 [95\% Cl: 0.85 to 0.98]). The CKD FI-LAB had the worst performance with a low and non-significant AUC value $(0.63$ [ $95 \% \mathrm{Cl}: 0.50$ to $0.78 ; \mathrm{p}=0.08])$. Supplementary Table 3 demonstrates cross-tabulation of the index test results by Frailty Phenotype frailty diagnosis.

Table 5 illustrates the diagnostic accuracy of frailty screening methods in CKD G4-5D categorised by age and dialysis-dependency. The frailty screening methods performed similarly in these sub-groups. Notable exceptions include the PRISMA-7 that had a nonsignificant AUC value in the $<65$ age group, the CKD FI-LAB that had a higher AUC value in the $<65$ years age group and hand grip strength that had a lower, though still reasonable, AUC value in the dialysis-dependent group. 


\section{Sensitivity Analyses}

Using the modified version of the Frailty Phenotype, 47 participants (52\%) were categorised as frail. When using this as the reference standard, the AUC value, though attenuated, remained high for all the physical assessments with walking speed again having the highest AUC value (walking speed AUC 0.84 [95\% Cl: 0.76 to 0.92], hand grip strength AUC 0.77 [95\% Cl: 0.67 to 0.86$]$ and SPPB AUC 0.81 [95\% Cl: 0.71 to 0.90$])$. 


\section{DISCUSSION}

To our knowledge, although frailty screening methods have been evaluated in CKD populations, this is the first study that evaluates the diagnostic accuracy of the Clinical Frailty Scale, PRISMA-7 and FI-LAB in a pre-dialysis and dialysis dependent CKD population [3,34-37]. Comparable to other reports, the prevalence of frailty increased with worsening kidney function in this cohort $[5,38,39]$. There was a similar age between non-frail and frail groups, highlighting that frailty is a syndrome that is not merely due to the ageing process. In addition, there was no statistically significant difference in the Charlson Comorbidity Scores between non-frail and frail participants. This is in accordance with Fried et al's conclusion that comorbidity, though a risk factor, is not synonymous with frailty [14]. Disability is a consequence of frailty, it is therefore unsurprising that within this cohort frail participants had a significantly worse performance status [14].

Studies have demonstrated a correlation between proinflammatory cytokines and white blood cell count with frailty in older adults [40-43]. Pro-inflammatory markers were not measured directly in our study, though there was no significant difference in other markers of inflammation between the non-frail and frail groups. Furthermore, low vitamin D levels have been associated with frailty in the older adult population $[42,44]$. However, there was no significant difference in vitamin D level between non-frail and frail groups in this cohort of CKD patients. These findings may be explained by the pathogenesis of frailty in CKD being distinct from the general older population, with factors such as the accumulation of uraemic toxins, reduced appetite, metabolic acidosis and anabolic hormone dysregulation contributing more prominently $[2,18]$. 
Walking speed, hand grip strength and the SPPB have all been proposed as frailty screening measures $[17,24,25,45,46]$. However, poor physical performance of the lower limbs, rather than upper limbs, is most predictive of outcomes in patients with CKD [47]. Roshanravan et al demonstrated that walking speed is associated with mortality in patients with CKD, unlike hand grip strength [47]. Within our study, walking speed was the superior frailty screening test with excellent equipoise between sensitivity/specificity and positive predicative value/negative predictive value. Though AUC values were attenuated when the physical measures were compared against a modified version of the Frailty Phenotype, they remained high with walking speed again having the best performance. Clegg et al demonstrated that, in the general older population, walking speed similarly performs well as a frailty screening measure [17].

Recognising that a frailty screening programme involving detailed physical assessments would be a time-demanding endeavour, several non-physical assessment frailty measures were studied, specifically the Clinical Frailty Scale, PRISMA-7, CKD FI and CKD FI-LAB. The Clinical Frailty Scale had the best performance of these measures in terms of identifying frailty. It also has the most extensive evidence base for predicting outcomes in patients with CKD $[15,48-50]$. Alfaadhel et al demonstrated that each point increase in the Clinical Frailty Scale score at dialysis initiation was associated with a mortality hazard ratio of $1.22(95 \% \mathrm{Cl}$ : 1.04 to 1.43) [49]. Pugh et al also showed an association with Clinical Frailty Scale scores and mortality in a group of CKD patients referred for pre-dialysis education (hazard ratio 1.35 [95\% Cl: 1.16-1.57]) [50]. Finally, lyasere et al demonstrated that higher Clinical Frailty Scale scores are associated with worse health-related quality of life in older patients receiving 
assisted peritoneal dialysis and haemodialysis [48]. The inter-rater reliability of the Clinical Frailty Scale requires further assessment in this population, including that of non-clinician users.

Though the FI correlates with the Frailty Phenotype in the older population, it has only been validated in a CKD cohort against a modified version of the Frailty Phenotype that substituted objective measurements for self-reported alternatives [37,51]. The suggested cut-off of $>0.21$ considerably over-estimated the prevalence of frailty and offered poor specificity [26]. A cut-off of $>0.32$ provided a better balance between sensitivity and specificity. Physical assessment variables were deliberately not incorporated within the CKD FI. The rationale for doing so was to improve its practicality when used as a frailty screening method, though in its current form, it is still a time-demanding measure. Further study is needed on the prognostic value of the FI in CKD populations and of the feasibility of incorporating such a screening method in nephrology outpatient services. The electronic Fl, described by Clegg et al, may improve the usability of the FI in CKD populations [52]. However, the construct validity of the electronic FI in patients with advanced CKD requires assessment. The FI-LAB, that consists of standard laboratory test result variables and systolic and diastolic blood pressure, has been studied in the older population [23]. It has been shown to correlate with the standard FI and to be predictive of outcomes in the older population $[23,53,54]$. However, the CKD FI-LAB only weakly correlated with the Frailty Phenotype and had a non-significant AUC value in the overall cohort, suggesting that it was not a useful test. This is especially disappointing given the wealth of laboratory variables available for the typical nephrology patient. 
The PRISMA-7 correlated moderately with the Frailty Phenotype, compared with the strong correlation for the Clinical Frailty Scale and the CKD FI. Using the suggested cut-off of $\geq 3$, the PRISMA 7 over-estimated the prevalence of frailty, though afforded a reasonable balance between sensitivity and specificity. This short questionnaire could certainly be incorporated into clinical practice, though the Clinical Frailty Scale should be considered in the first instance given its superior diagnostic accuracy.

Notwithstanding the practical usefulness of this study, there are recognised limitations. Although the study's sample size allows an accurate assessment of the screening tests' correlation with the Frailty Phenotype and their respective AUC values, thus providing a valuable measure of their diagnostic accuracy, the precision of the screening tests' sensitivity and specificity would benefit from being examined in a larger sample. Furthermore, our data was obtained from a single-centre, with a predominantly Caucasian population. The high proportion of Caucasian participants recruited to the study may also reflect a necessary exclusion criterion, i.e. patients who do not have sufficient understanding of the English language to complete study questionnaires [55]. Ethnicity appears to affect the expression of frailty with studies showing a higher prevalence of frailty in those of Black and Hispanic ethnicity, though it has been reported that frailty is similarly hazardous regardless of ethnicity in those with dialysis-dependent CKD [4,56,57]. Further investigation within more culturally diverse cohorts is needed to verify the present results in those cohorts and confirm the generalisability of our results. Finally, the frailty screening methods used in our study were only performed at one time point and therefore we cannot report their reliability. Other studies have reported the reliability of physical assessment 
measures, though the reliability of the Clinical Frailty Scale and PRISMA-7 have not been assessed in an advanced CKD cohort to our knowledge [58-60].

\section{CONCLUSIONS}

Frailty is highly prevalent in CKD with the prevalence increasing with worsening kidney function. Walking speed is a very useful frailty screening measure in patients with advanced CKD, as is the case in the general older population [17]. If it is not practical to perform a physical assessment, a non-physical assessment of frailty should be performed. The Clinical Frailty Scale was the most accurate non-physical assessment and currently has the strongest evidence base for prognostication in advanced CKD populations [48-50]. Further study is needed on the optimum management strategies for frail patients with CKD. Walking speed or a Clinical Frailty Scale assessment could be used to identify physically frail patients for randomised controlled trials of management strategies that aim to improve outcomes of this vulnerable patient group. 


\section{REFERENCES}

1 Clegg A, Young J, lliffe S, Rikkert MO, Rockwood K: Frailty in elderly people. Lancet 2013;381:752-762.

2 Kim JC, Kalantar-Zadeh K, Kopple JD: Frailty and protein-energy wasting in elderly patients with end stage kidney disease. J Am Soc Nephrol 2013;24:337-351.

3 Chowdhury R, Peel NM, Krosch M, Hubbard RE: Frailty and chronic kidney disease: A systematic review. Arch Gerontol Geriatr 2016;68:135-142.

4 Johansen KL, Chertow GM, Jin C, Kutner NG: Significance of frailty among dialysis patients. J Am Soc Nephrol 2007;18:2960-2967.

5 Roshanravan B, Khatri M, Robinson-Cohen C, Levin G, Patel KV, de Boer IH, Seliger S, Ruzinski J, Himmelfarb J, Kestenbaum B: A prospective study of frailty in nephrologyreferred patients with CKD. Am J Kidney Dis 2012;60:912-921.

6 Bao Y, Dalrymple L, Chertow GM, Kaysen GA, Johansen KL: Frailty, dialysis initiation, and mortality in end-stage renal disease. Arch Intern Med 2012;172:1071-1077.

7 McAdams-DeMarco MA, Law A, Salter ML, Boyarsky B, Gimenez L, Jaar BG, Walston JD, Segev DL: Frailty as a novel predictor of mortality and hospitalization in individuals of all ages undergoing hemodialysis. J Am Geriatr Soc 2013;61:896-901.

8 McAdams-DeMarco MA, Suresh S, Law A, Salter ML, Gimenez LF, Jaar BG, Walston JD, Segev DL: Frailty and falls among adult patients undergoing chronic hemodialysis: a prospective cohort study. BMC Nephrol 2013;14:224.

9 McAdams-DeMarco MA, Law A, King E, Orandi B, Salter M, Gupta N, Chow E, Alachkar N, Desai N, Varadhan R, Walston J, Segev DL: Frailty and mortality in kidney transplant recipients. Am J Transplant 2015;15:149-154. 
Parekh RS, Segev DL, Sozio SM: Frailty and Cognitive Function in Incident Hemodialysis Patients. Clin J Am Soc Nephrol 2015;10:2181-2189.

11 Mansur HN, Colugnati FA, Grincenkov FR, Bastos MG: Frailty and quality of life: a cross-sectional study of Brazilian patients with pre-dialysis chronic kidney disease. Health Qual Life Outcomes 2014;12:27.

12 Lee SJ, Son H, Shin SK: Influence of frailty on health-related quality of life in predialysis patients with chronic kidney disease in Korea: a cross-sectional study. Health Qual Life Outcomes 2015;13:70.

13 Morley JE, Vellas B, van Kan GA, Anker SD, Bauer JM, Bernabei R, Cesari M, Chumlea WC, Doehner W, Evans J, Fried LP, Guralnik JM, Katz PR, Malmstrom TK, McCarter RJ, Gutierrez Robledo LM, Rockwood K, von Haehling S, Vandewoude MF, Walston J: Frailty consensus: a call to action. J Am Med Dir Assoc 2013;14:392-397.

14 Fried LP, Tangen CM, Walston J, Newman AB, Hirsch C, Gottdiener J, Seeman T, Tracy R, Kop WJ, Burke G, McBurnie MA: Frailty in older adults: evidence for a phenotype. J Gerontol A Biol Sci Med Sci 2001;56:M146-156.

15 Rockwood K, Song X, MacKnight C, Bergman H, Hogan DB, McDowell I, Mitnitski A: A global clinical measure of fitness and frailty in elderly people. CMAJ 2005;173:489-495. 16 Salter ML, Gupta N, Massie AB, McAdams-DeMarco MA, Law AH, Jacob RL, Gimenez LF, Jaar BG, Walston JD, Segev DL: Perceived frailty and measured frailty among adults undergoing hemodialysis: a cross-sectional analysis. BMC Geriatr 2015;15:52.

17 Clegg A, Rogers L, Young J: Diagnostic test accuracy of simple instruments for identifying frailty in community-dwelling older people: a systematic review. Age Ageing 2015;44:148-152. 

and chronic kidney disease: current evidence and continuing uncertainties. Clin Kidney J 2018;11:236-245.

19 Keller HH, McKenzie JD, Goy RE: Construct validation and test-retest reliability of the seniors in the community: risk evaluation for eating and nutrition questionnaire. J Gerontol A Biol Sci Med Sci 2001;56:M552-558.

20 Kukull WA, Larson EB, Teri L, Bowen J, McCormick W, Pfanschmidt ML: The MiniMental State Examination score and the clinical diagnosis of dementia. J Clin Epidemiol 1994;47:1061-1067.

21 Raiche M, Hebert R, Dubois MF: PRISMA-7: a case-finding tool to identify older adults with moderate to severe disabilities. Arch Gerontol Geriatr 2008;47:9-18.

22 Searle SD, Mitnitski A, Gahbauer EA, Gill TM, Rockwood K: A standard procedure for creating a frailty index. BMC Geriatr 2008;8:24.

23 Howlett SE, Rockwood MR, Mitnitski A, Rockwood K: Standard laboratory tests to identify older adults at increased risk of death. BMC Med 2014;12:171.

24 Guralnik JM, Simonsick EM, Ferrucci L, Glynn RJ, Berkman LF, Blazer DG, Scherr PA, Wallace RB: A short physical performance battery assessing lower extremity function: association with self-reported disability and prediction of mortality and nursing home admission. J Gerontol 1994;49:M85-94.

25 Turner G, Clegg A, British Geriatrics S, Age UK, Royal College of General P: Best practice guidelines for the management of frailty: a British Geriatrics Society, Age UK and Royal College of General Practitioners report. Age Ageing 2014;43:744-747.

26 Blodgett J, Theou O, Kirkland S, Andreou P, Rockwood K: Frailty in NHANES: Comparing the frailty index and phenotype. Arch Gerontol Geriatr 2015;60:464-470. 
27 Roberts HC, Denison HJ, Martin HJ, Patel HP, Syddall H, Cooper C, Sayer AA: A review of the measurement of grip strength in clinical and epidemiological studies: towards a standardised approach. Age Ageing 2011;40:423-429.

28 Lauretani F, Russo CR, Bandinelli S, Bartali B, Cavazzini C, Di lorio A, Corsi AM, Rantanen T, Guralnik JM, Ferrucci L: Age-associated changes in skeletal muscles and their effect on mobility: an operational diagnosis of sarcopenia. J Appl Physiol (1985) 2003;95:1851-1860.

29 da Camara SM, Alvarado BE, Guralnik JM, Guerra RO, Maciel AC: Using the Short Physical Performance Battery to screen for frailty in young-old adults with distinct socioeconomic conditions. Geriatr Gerontol Int 2013;13:421-428.

30 Holm S: A Simple Sequentially Rejective Multiple Test Procedure. Scandinavian Journal of Statistics 1979;6:65-70.

31 Gaetano J: (2013). Holm-Bonferroni sequential correction: An EXCEL calculator (1.2) [Microsoft Excel workbook]. [cited 2018 Aug 8]. Available from https://www.researchgate.net/publication/242331583_HolmBonferroni_Sequential_Correction_An_EXCEL_Calculator_-_Ver._1.2 . doi:10.13140/RG.2.1.3920.0481

32 Bonett DG, Wright TA: Sample size requirements for estimating pearson, kendall and spearman correlations. Psychometrika 2000;65:23-28.

33 Obuchowski NA: Sample size calculations in studies of test accuracy. Stat Methods Med Res 1998;7:371-392.

34 Johansen KL, Dalrymple LS, Delgado C, Kaysen GA, Kornak J, Grimes B, Chertow GM: Comparison of self-report-based and physical performance-based frailty definitions among patients receiving maintenance hemodialysis. Am J Kidney Dis 2014;64:600-607. 
Screening Tools for Elderly Patients Incident to Dialysis. Clin J Am Soc Nephrol 2017;12:1480-1488.

36 van Munster BC, Drost D, Kalf A, Vogtlander NP: Discriminative value of frailty screening instruments in end-stage renal disease. Clin Kidney J 2016;9:606-610.

37 Hubbard RE, Peel NM, Smith M, Dawson B, Lambat Z, Bak M, Best J, Johnson DW: Feasibility and construct validity of a Frailty index for patients with chronic kidney disease. Australas J Ageing 2015;34:E9-12.

38 Ballew SH, Chen Y, Daya NR, Godino JG, Windham BG, McAdams-DeMarco M, Coresh J, Selvin E, Grams ME: Frailty, Kidney Function, and Polypharmacy: The Atherosclerosis Risk in Communities (ARIC) Study. Am J Kidney Dis 2017;69:228-236. 39 Collard RM, Boter H, Schoevers RA, Oude Voshaar RC: Prevalence of frailty in community-dwelling older persons: a systematic review. J Am Geriatr Soc 2012;60:14871492.

40 Ershler WB, Keller ET: Age-associated increased interleukin-6 gene expression, latelife diseases, and frailty. Annu Rev of Med 2000;51:245-270.

41 Leng SX, Hung W, Cappola AR, Yu Q, Xue QL, Fried LP: White blood cell counts, insulin-like growth factor-1 levels, and frailty in community-dwelling older women. J Gerontol A Biol Sci Med Sci 2009;64:499-502.

42 Puts MT, Visser M, Twisk JW, Deeg DJ, Lips P: Endocrine and inflammatory markers as predictors of frailty. Clinical Endocrinol (Oxf) 2005;63:403-411.

43 Schaap LA, Pluijm SM, Deeg DJ, Harris TB, Kritchevsky SB, Newman AB, Colbert LH, Pahor M, Rubin SM, Tylavsky FA, Visser M, Health ABCS: Higher inflammatory marker levels 
in older persons: associations with 5-year change in muscle mass and muscle strength. J Gerontol A Biol Sci Med Sci 2009;64:1183-1189.

44 Bruyere O, Cavalier E, Buckinx F, Reginster JY: Relevance of vitamin D in the pathogenesis and therapy of frailty. Curr Opin Clin Nutr Metab Care 2017;20:26-29. 45 Syddall H, Cooper C, Martin F, Briggs R, Aihie Sayer A: Is grip strength a useful single marker of frailty? Age Ageing 2003;32:650-656.

46 Pavasini R, Guralnik J, Brown JC, di Bari M, Cesari M, Landi F, Vaes B, Legrand D, Verghese J, Wang C, Stenholm S, Ferrucci L, Lai JC, Bartes AA, Espaulella J, Ferrer M, Lim JY, Ensrud KE, Cawthon P, Turusheva A, Frolova E, Rolland Y, Lauwers V, Corsonello A, Kirk GD, Ferrari R, Volpato S, Campo G: Short Physical Performance Battery and all-cause mortality: systematic review and meta-analysis. BMC Med 2016;14:215.

47 Roshanravan B, Robinson-Cohen C, Patel KV, Ayers E, Littman AJ, de Boer IH, Ikizler TA, Himmelfarb J, Katzel LI, Kestenbaum B, Seliger S: Association between physical performance and all-cause mortality in CKD. J Am Soc Nephrol 2013;24:822-830. 48 Iyasere OU, Brown EA, Johansson L, Huson L, Smee J, Maxwell AP, Farrington K, Davenport A: Quality of Life and Physical Function in Older Patients on Dialysis: A Comparison of Assisted Peritoneal Dialysis with Hemodialysis. Clin J Am Soc Nephrol 2016;11:423-430.

49 Alfaadhel TA, Soroka SD, Kiberd BA, Landry D, Moorhouse P, Tennankore KK: Frailty and mortality in dialysis: evaluation of a clinical frailty scale. Clin J Am Soc Nephrol $2015 ; 10: 832-840$.

50 Pugh J, Aggett J, Goodland A, Prichard A, Thomas N, Donovan K, Roberts G: Frailty and comorbidity are independent predictors of outcome in patients referred for pre-dialysis education. Clin Kidney J 2016;9:324-329. 
51 Rockwood K, Andrew M, Mitnitski A: A comparison of two approaches to measuring frailty in elderly people. J Gerontol A Biol Sci Med Sci 2007;62:738-743.

52 Clegg A, Bates C, Young J, Ryan R, Nichols L, Ann Teale E, Mohammed MA, Parry J, Marshall T: Development and validation of an electronic frailty index using routine primary care electronic health record data. Age Ageing 2016;45:353-360.

53 Rockwood K, McMillan M, Mitnitski A, Howlett SE: A Frailty Index Based on Common Laboratory Tests in Comparison With a Clinical Frailty Index for Older Adults in Long-Term Care Facilities. J Am Med Dir Assoc 2015;16:842-847.

54 Blodgett JM, Theou O, Howlett SE, Wu FC, Rockwood K: A frailty index based on laboratory deficits in community-dwelling men predicted their risk of adverse health outcomes. Age Ageing 2016;45:463-468.

55 Quay TA, Frimer L, Janssen PA, Lamers Y: Barriers and facilitators to recruitment of South Asians to health research: a scoping review. BMJ Open 2017;7:e014889.

56 Bandeen-Roche K, Seplaki CL, Huang J, Buta B, Kalyani RR, Varadhan R, Xue QL, Walston JD, Kasper JD: Frailty in Older Adults: A Nationally Representative Profile in the United States. J Gerontol A Biol Sci Med Sci 2015;70:1427-1434.

57 Reese PP, Cappola AR, Shults J, Townsend RR, Gadegbeku CA, Anderson C, Baker JF, Carlow D, Sulik MJ, Lo JC, Go AS, Ky B, Mariani L, Feldman HI, Leonard MB: Physical performance and frailty in chronic kidney disease. Am J Nephrol 2013;38:307-315. 58 Segura-Orti E, Martinez-Olmos FJ: Test-retest reliability and minimal detectable change scores for sit-to-stand-to-sit tests, the six-minute walk test, the one-leg heel-rise test, and handgrip strength in people undergoing hemodialysis. Phys Ther 2011;91:12441252. 
59 Ortega-Perez de Villar L, Martinez-Olmos FJ, Junque-Jimenez A, Amer-Cuenca JJ, Martinez-Gramage J, Mercer T, Segura-Orti E: Test-retest reliability and minimal detectable change scores for the short physical performance battery, one-legged standing test and timed up and go test in patients undergoing hemodialysis. PloS One 2018;13:e0201035. 60 Wilkinson TJP, Xenophontos SM, Gould DWP, Vogt BPP, Viana JLP, Smith ACP, Watson ELP: Test-retest reliability, validation, and "minimal detectable change" scores for frequently reported tests of objective physical function in patients with non-dialysis chronic kidney disease. Physiother Theory Pract 2018:1-12. 


\section{ACKNOWLEDGEMENTS}

Dr Chris Sutton advised on the sample size calculation for the study. Dr Miland Joshi and Dr Helene Thygesen provided additional advice on statistical analyses. Mr Alastair Petrie and Miss Atinuke Afolabi assisted in study assessments.

\section{CONFLICTS OF INTEREST}

This research did not receive any specific grant from funding agencies in the public, commercial or not-for-profit sectors. Dr Nixon receives non-financial support from the NIHR Lancashire Clinical Research Facility. Unrelated to this body of work, Dr Dhaygude has received lecture fees from speaking at the invitation of MSD and received travel support from Pharmacosmos. The views expressed are those of the authors and not necessarily those of the NHS, the NIHR or the Department of Health.

\section{STATEMENT OF ETHICS}

Ethical approval was obtained from the NHS Health Research Authority (IRAS Project ID 216379). Formal written consent was obtained for all participants. 
TABLES

Table 1. The Frailty Phenotype Assessment.

\begin{tabular}{|c|c|c|}
\hline Frailty Criteria & \multicolumn{2}{|l|}{ Measure } \\
\hline Unintentional Weight Loss & \multicolumn{2}{|c|}{$\geq 10$ pounds or $\geq 5 \%$ body weight over the preceding 12 months. } \\
\hline \multirow[t]{6}{*}{ Weakness } & \multicolumn{2}{|l|}{ Hand grip strength frailty criterion cut offs: } \\
\hline & Men & Women \\
\hline & $\mathrm{BMI} \leq 24: \leq 29 \mathrm{~kg}$ & $\mathrm{BMI} \leq 23: \leq 17 \mathrm{~kg}$ \\
\hline & BMI 24.1-26: $\leq 30 \mathrm{~kg}$ & BMI 23.1-26: $\leq 17.3 \mathrm{~kg}$ \\
\hline & BMI 26.1-28: $\leq 30 \mathrm{~kg}$ & BMI 26.1-29: $\leq 18$ kg \\
\hline & $\mathrm{BMI}>28: \leq 32 \mathrm{~kg}$ & $\mathrm{BMI}>29: \leq 21 \mathrm{~kg}$ \\
\hline \multirow[t]{11}{*}{ Self-perceived Exhaustion } & \multirow{2}{*}{\multicolumn{2}{|c|}{$\begin{array}{l}\text { Participants asked two statements from the Center for Epidemiological Studies Depression } \\
\text { Scale: }\end{array}$}} \\
\hline & & \\
\hline & \multicolumn{2}{|c|}{ 1. I felt that everything I did was an effort. } \\
\hline & \multicolumn{2}{|l|}{ 2. I could not get going. } \\
\hline & \multicolumn{2}{|l|}{ Participants then asked: } \\
\hline & \multicolumn{2}{|c|}{ 'How often did you feel this?' and provided the following scale: } \\
\hline & \multicolumn{2}{|l|}{$0=$ rarely or none of the time } \\
\hline & \multicolumn{2}{|l|}{$1=$ some of the time } \\
\hline & \multicolumn{2}{|l|}{$2=$ moderate amount of the time } \\
\hline & \multicolumn{2}{|l|}{$3=$ most of the time } \\
\hline & \multicolumn{2}{|l|}{ Frailty criterion: answers $\geq 2$} \\
\hline \multirow[t]{4}{*}{ Slowness } & \multicolumn{2}{|l|}{ Walking speed frailty criterion cut offs: } \\
\hline & Men & Women \\
\hline & Height $\leq 173 \mathrm{~cm}: \geq 7$ seconds $(\leq 0.65 \mathrm{~m} / \mathrm{s}$ ) & Height $\leq 159 \mathrm{~cm}: \geq 7$ seconds $(\leq 0.65 \mathrm{~m} / \mathrm{s})$ \\
\hline & Height $>173 \mathrm{~cm}: \geq 6$ seconds $(\leq 0.76 \mathrm{~m} / \mathrm{s})$ & Height $>159 \mathrm{~cm}: \geq 6$ seconds $(\leq 0.76 \mathrm{~m} / \mathrm{s})$ \\
\hline Low Physical Activity & \multicolumn{2}{|c|}{$\begin{array}{l}\text { Modified version of the Minnesota Leisure Time Questionnaire used to assess energy } \\
\text { expenditure per week. Frailty criterion: Men }<383 \text { Kcals/week, Women }<270 \text { Kcals/week. }\end{array}$} \\
\hline
\end{tabular}


Table 2. The PRISMA-7 Questionnaire Frailty Screening Tool.

\begin{tabular}{lc}
\hline Question & Answer \\
\hline 1. Are you more than 85 years old? & Yes/No \\
\hline 2. Male? & Yes/No \\
\hline 3. In general, do you have any health problems that require you to limit your activities? & Yes/No \\
\hline 4. Do you need someone to help you on a regular basis? & Yes/No \\
\hline 5. In general, do you have any health problems that require you to stay at home? & Yes/No \\
\hline 6. In case of need, can you count on someone close to you? & Yes/No \\
\hline 7. Do you regularly use a cane, a walker or a wheelchair to move about? & Yes/No \\
\hline \multicolumn{2}{c}{ Total Number of 'Yes' Answers: }
\end{tabular}


Table 3. Baseline Demographics and Clinical Characteristics of Non-Frail and Frail Participants (Defined by The Frailty Phenotype) in CKD G4-5D.

\begin{tabular}{|c|c|c|c|}
\hline & Non-Frail $(n=71)$ & Frail $(n=19)$ & Adjusted P Value \\
\hline Age, years & $68( \pm 13)$ & $73( \pm 11)$ & 1.00 \\
\hline Female, \% & $30(42)$ & $15(79)$ & 0.10 \\
\hline Body Mass Index, kg/m² & $29( \pm 6)$ & $28( \pm 6)$ & 1.00 \\
\hline \multicolumn{4}{|l|}{ Treatment Modality, \% } \\
\hline - $\quad$ Pre-Dialysis & $51(72)$ & $9(47)$ & 0.99 \\
\hline - Haemodialysis & $20(28)$ & $10(53)$ & \\
\hline Charlson Comorbidity Index & $3(2)$ & $4(4)$ & 1.00 \\
\hline Diabetes Mellitus, \% & $16(23)$ & $8(42)$ & 1.00 \\
\hline Karnofsky Score & $80(20)$ & $60(20)$ & $<0.001$ \\
\hline Medications & $8( \pm 3)$ & $11( \pm 5)$ & 0.08 \\
\hline Current or ex-smoker, \% & $40(56)$ & $9(47)$ & 1.00 \\
\hline MMSE Score $\leq 27, \%(n=87)$ & $13(19)$ & $5(29)$ & 1.00 \\
\hline Fall within last 6 months, \% & $11(15)$ & $5(26)$ & 1.00 \\
\hline SCREEN I $\leq 50, \%$ & $53(75)$ & $17(89)$ & 1.00 \\
\hline \multicolumn{4}{|l|}{ Blood Pressure, $\mathrm{mmHg}$} \\
\hline - Systolic & $148( \pm 19)$ & $149( \pm 25)$ & 1.00 \\
\hline - Diastolic & $74( \pm 14)$ & $67( \pm 15)$ & 0.92 \\
\hline \multicolumn{4}{|l|}{ Laboratory Variables } \\
\hline - Haemoglobin, g/L & $117.6( \pm 12.7)$ & $111.4( \pm 14.6)$ & 1.00 \\
\hline - White Cell Count, $\times 10^{9} / \mathrm{L}$ & $7.6( \pm 2.5)$ & $8.0( \pm 2.6)$ & 1.00 \\
\hline - Neutrophil/Lymphocyte Ratio & $3.1(2.0)$ & $3.3(1.5)$ & 1.00 \\
\hline - $\quad$ Corrected Calcium, mmol/L & $2.3( \pm 0.1)$ & $2.3( \pm 0.1)$ & 1.00 \\
\hline - $\quad$ Phosphate, $\mathrm{mmol} / \mathrm{L}$ & $1.4(0.4)$ & $1.5(0.6)$ & 1.00 \\
\hline - $\quad$ Alkaline Phosphatase, U/L & $86.0(38.0)$ & $92.0(53.0)$ & 1.00 \\
\hline - $\quad$ Albumin, $g / L$ & $41.3( \pm 3.3)$ & $39.6( \pm 3.3)$ & 1.00 \\
\hline - $\quad$ Total Protein, g/L & $67.7( \pm 5.3)$ & $66.2( \pm 6.6)$ & 1.00 \\
\hline$-\quad C R P, \mathrm{mg} / \mathrm{L}(\mathrm{n}=64)$ & $5.0(10.7)$ & $5.5(8.4)$ & 1.00 \\
\hline - $\quad$ Ferritin, $\mu g / L(n=73)$ & $385.0(594.3)$ & $503.0(533.0)$ & 1.00 \\
\hline - $\quad$ PTH, pmol/L (n=81) & $19.8(23.3)$ & $26.2(25.0)$ & 1.00 \\
\hline - $\quad$ Vitamin D, nmol/L ( $n=48)$ & $58.0(35.5)$ & $55.0(60.0)$ & 1.00 \\
\hline
\end{tabular}

MMSE, Mini-Mental State Examination. Data presented as number (\%), mean ( \pm SD) or median (IQR). 
Table 4. Diagnostic Accuracy of Frailty Screening Methods (Using the Frailty Phenotype as Reference Standard) in CKD G4-5D.

\begin{tabular}{|c|c|c|c|c|c|c|c|c|c|c|c|c|}
\hline & $\begin{array}{l}\text { Correlation Coefficient } \\
(95 \% \mathrm{Cl})\end{array}$ & P Value & $\begin{array}{l}\text { AUC } \\
(95 \% \mathrm{Cl})\end{array}$ & P Value & Cut-off & $\begin{array}{l}\text { Frailty Prevalence } \\
\text { (\%) }\end{array}$ & Sensitivity (95\%Cl) & Specificity (95\%Cl) & $\begin{array}{l}\text { PPV } \\
(95 \% \mathrm{Cl})\end{array}$ & $\begin{array}{l}\text { NPV } \\
(95 \% \mathrm{Cl})\end{array}$ & $\begin{array}{l}\text { LR+ } \\
(95 \% \text { CI) }\end{array}$ & $\begin{array}{l}\text { LR- } \\
(95 \% \mathrm{Cl})\end{array}$ \\
\hline \multirow[t]{2}{*}{ Clinical Frailty Scale } & $0.77(0.66$ to 0.85$)$ & $<0.001$ & 0.90 (0.84 to 0.97$)$ & $<0.001$ & $\geq 5$ & $24(27)$ & $0.79(0.57$ to 0.91$)$ & 0.87 (0.78 to 0.93$)$ & $0.63(0.43$ to 0.79$)$ & $0.94(0.85$ to 0.98$)$ & $6.23(3.28$ to 12.00$)$ & $0.24(0.10$ to 0.50$)$ \\
\hline & & & & & $\geq 4$ & $51(57)$ & 1.00 (0.83 to 1.00$)$ & 0.55 (0.43 to 0.66$)$ & $0.37(0.25$ to 0.51$)$ & 1.00 (0.91 to 1.00$)$ & 2.22 (1.64 to 2.88$)$ & $0.00(0.00$ to 0.31$)$ \\
\hline PRISMA-7 & 0.64 (0.50 to 0.75$)$ & $<0.001$ & 0.83 (0.73 to 0.93$)$ & $<0.001$ & $\geq 3$ & $45(50)$ & 0.89 (0.69 to 0.97$)$ & 0.61 (0.49 to 0.71$)$ & 0.38 (0.25 to 0.52$)$ & $0.96(0.85$ to 0.99$)$ & 2.27 (1.59 to 3.17 ) & $0.17(0.05$ to 0.53$)$ \\
\hline \multirow[t]{2}{*}{ CKD FI } & $0.75(0.65$ to 0.81$)$ & $<0.001$ & 0.88 (0.81 to 0.96$)$ & $<0.001$ & $>0.21$ & $64(71)$ & 1.00 (0.83 to 1.00$)$ & $0.37(0.26$ to 0.48$)$ & $0.30(0.20$ to 0.42$)$ & $1.00(0.87$ to 1.00$)$ & 1.58 (1.22 to 1.89$)$ & $0.00(0.00$ to 0.47$)$ \\
\hline & & & & & $>0.32$ & $41(46)$ & 0.95 (0.75 to 0.99$)$ & 0.68 (0.56 to 0.77$)$ & 0.44 (0.30 to 0.59 ) & 0.98 (0.89 to 1.00$)$ & $2.92(2.05$ to 4.22$)$ & 0.08 (0.01 to 0.37 ) \\
\hline CKD FI-LAB* & 0.26 (0.05 to 0.46$)$ & 0.02 & $0.63(0.50-0.77)$ & 0.08 & & . & & & - & & & - \\
\hline \multirow[t]{2}{*}{ Walking Speed } & $0.70(0.55$ to 0.80$)$ & $<0.001$ & $0.97(0.93$ to 1.00$)$ & $<0.001$ & Frailty Phenotype Criterion & $19(21)$ & 0.84 (0.62 to 0.94$)$ & 0.96 (0.88 to 0.99 ) & 0.84 (0.62 to 0.94$)$ & 0.96 (0.88 to 0.99$)$ & 19.93 (7.02 to 58.95$)$ & $0.16(0.06$ to 0.39$)$ \\
\hline & & & & & $\leq 0.8 \mathrm{~m} / \mathrm{s}$, or unable & $28(31)$ & 0.95 (0.75 to 0.99$)$ & 0.86 (0.76 to 0.92$)$ & 0.64 (0.46 to 0.79 ) & 0.98 (0.91 to 1.00$)$ & 6.72 (3.87 to 12.18$)$ & 0.06 (0.01 to 0.29$)$ \\
\hline \multirow[t]{2}{*}{ Hand Grip Strength } & $-0.62(-0.73$ to -0.48$)$ & $<0.001$ & 0.87 (0.78 to 0.96$)$ & $<0.001$ & Frailty Phenotype Criterion & $43(48)$ & 1.00 (0.83 to 1.00$)$ & 0.66 (0.55 to 0.76$)$ & 0.44 (0.30 to 0.59$)$ & $1.00(0.92$ to 1.00$)$ & 2.96 (2.09 to 4.10$)$ & $0.00(0.00$ to 0.26$)$ \\
\hline & & & & & Men <30kg; Women <20kg & $46(51)$ & 0.95 (0.75 to 0.99 ) & 0.61 (0.49 to 0.71$)$ & 0.39 (0.26 to 0.54$)$ & 0.98 (0.88 to 1.00$)$ & 2.40 (1.74 to 3.31$)$ & $0.09(0.02$ to 0.41$)$ \\
\hline \multirow[t]{2}{*}{ SPPB } & $-0.66(-0.78$ to -0.51$)$ & $<0.001$ & 0.92 (0.86 to 0.97$)$ & $<0.001$ & $<10$ & $53(59)$ & 1.00 (0.83 to 1.00$)$ & 0.52 (0.41 to 0.63$)$ & 0.36 (0.24 to 0.49$)$ & 1.00 (0.91 to 1.00$)$ & 2.09 (1.56 to 2.67$)$ & $0.00(0.00$ to 0.33$)$ \\
\hline & & & & & $<9$ & $35(39)$ & 1.00 (0.83 to 1.00$)$ & 0.77 (0.66 to 0.86$)$ & $0.54(0.38$ to 0.70$)$ & 1.00 (0.93 to 1.00$)$ & $4.44(2.86$ to 6.81$)$ & $0.00(0.00$ to 0.22$)$ \\
\hline
\end{tabular}

AUC, Area Under the Curve; Cl, Confidence Interval; PPV, Positive Predictive Value; NPV, Negative Predictive Value; LR+, Positive Likelihood

Ratio; LR-, Negative Likelihood Ratio. *Six participants did not have the pre-requisite number of variables to complete the CKD FI-LAB. 
Table 5. Diagnostic Accuracy of Frailty Screening Methods (Using the Frailty Phenotype as Reference Standard) in CKD G4-5D Categorised by Age and Dialysis-Dependency.

\begin{tabular}{|c|c|c|c|}
\hline & & AUC Value $(95 \% \mathrm{Cl})$ & P Value \\
\hline \multicolumn{4}{|c|}{ Clinical Frailty Scale } \\
\hline- & $\geq 65$ years & 0.89 (0.80 to 0.98$)$ & $<0.001$ \\
\hline- & $<65$ years & 0.93 (0.83 to 1.00$)$ & 0.003 \\
\hline- & Pre-Dialysis & 0.87 (0.76 to 0.98$)$ & 0.001 \\
\hline- & Dialysis-Dependent & 0.93 (0.83 to 1.00$)$ & $<0.001$ \\
\hline \multicolumn{4}{|c|}{ PRISMA-7 } \\
\hline- & $\geq 65$ years & 0.85 (0.76 to 0.94$)$ & $<0.001$ \\
\hline- & $<65$ years & $0.76(0.51$ to 1.00$)$ & 0.07 \\
\hline- & Pre-Dialysis & 0.81 (0.66 to 0.95$)$ & 0.004 \\
\hline- & Dialysis-Dependent & $0.86(0.71$ to 1.00$)$ & 0.002 \\
\hline \multicolumn{4}{|c|}{ CKD FI } \\
\hline- & $\geq 65$ years & 0.89 (0.80 to 0.97$)$ & $<0.001$ \\
\hline- & $<65$ years & 0.91 (0.80 to 1.00$)$ & 0.01 \\
\hline- & Pre-Dialysis & $0.86(0.74$ to 0.97$)$ & 0.001 \\
\hline- & Dialysis-Dependent & 0.93 (0.84 to 1.00$)$ & $<0.001$ \\
\hline \multicolumn{4}{|c|}{ CKD FI-LAB ${ }^{*}$} \\
\hline- & $\geq 65$ years & 0.59 (0.43 to 0.75$)$ & 0.32 \\
\hline- & $<65$ years & $0.83(0.66$ to 1.00$)$ & 0.02 \\
\hline- & Pre-Dialysis & 0.61 (0.42 to 0.81$)$ & 0.3 \\
\hline- & Dialysis-Dependent & 0.58 (0.36 to 0.79$)$ & 0.51 \\
\hline \multicolumn{4}{|c|}{ Walking Speed } \\
\hline- & $\geq 65$ years & 0.96 (0.91 to 1.00$)$ & $<0.001$ \\
\hline- & $<65$ years & 0.97 (0.91 to 1.00$)$ & 0.001 \\
\hline- & Pre-Dialysis & $0.98(0.94$ to 1.00$)$ & $<0.001$ \\
\hline- & Dialysis-Dependent & 0.96 (0.90 to 1.00$)$ & $<0.001$ \\
\hline \multicolumn{4}{|c|}{ Hand Grip Strength } \\
\hline- & $\geq 65$ years & 0.86 (0.76 to 0.97$)$ & $<0.001$ \\
\hline- & $<65$ years & $0.88(0.73$ to 1.00$)$ & 0.01 \\
\hline- & Pre-Dialysis & 0.91 (0.81 to 1.00$)$ & $<0.001$ \\
\hline- & Dialysis-Dependent & 0.78 (0.60 to 0.96$)$ & 0.02 \\
\hline \multicolumn{4}{|l|}{ SPPB } \\
\hline- & $\geq 65$ years & $0.90(0.83$ to 0.98$)$ & $<0.001$ \\
\hline- & $<65$ years & 0.97 (0.92 to 1.00$)$ & 0.001 \\
\hline- & Pre-Dialysis & 0.91 (0.83 to 0.98$)$ & $<0.001$ \\
\hline- & Dialysis-Dependent & 0.92 (0.83 to 1.00$)$ & $<0.001$ \\
\hline
\end{tabular}

AUC, Area Under the Curve; $\mathrm{Cl}$, Confidence Interval. *Six participants did not have the prerequisite number of variables to complete the CKD FI-LAB. 


\section{FIGURE LEGENDS}

Figure 1. The Clinical Frailty Scale.

The 9-point Clinical Frailty Scale was adapted from the 7-point scale used in the Canadian Study of Health and Aging and has been reprinted with permission of Geriatric Medicine Research, Dalhousie University, Halifax, Nova Scotia, Canada.

\section{Clinical Frailty Scale*}

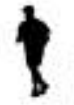

Very Fit - Feople who are robust, active, energetic and motruated These people commonky exercise regularly. They are among the fittest for their age 2 Well - People who have no active disease symptoms but are less fit than category I. Often they cxercise or are very active occasionally, eg semsorially. 3 Managing Well-People whose medical problems are well controlled, but are not regularly active beyond routre walking.

\footnotetext{
8 4 Vulnerable - While not dependent an others for Gily help, often symptoms limit activities. A comman complant is being "slowed up" andior being tired during the days
}

\section{Mildly Frail - These people often have moce} evident slowing, and need thelp in high order IADLs (finarices, tramportation heavy houscwork, medications). Typically mid fraitty promessively impairs shopping and walking outside abre meal preparatian and housework.

6 Moderately Frail - People need help with all outside activities and with keeping house Inside, the often have problems with stairs and reed help with bathing and might need mirimal assostance (cuing standby) with dressing

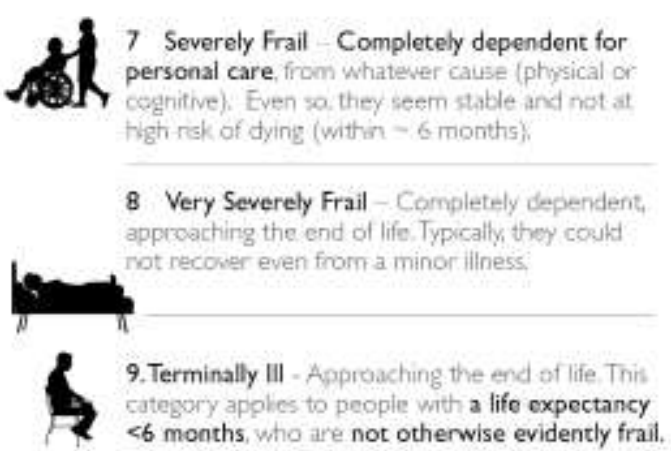

Scoring fraity in people with dementia

The oegree of rasty corresponds to the degree of dementia Common symptorns in mild dementia include forgettrig the detals of a recent exent, though it lil romembening the event itself ripesing the same questionstory and social whidramal.

In moderate demencla, recent memory is very impaiced even though they semingly can ramerniber stheir past. life events wel They can do persoral care with promptring

in severe dementia tivef carrut do persunal care without tielp

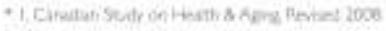

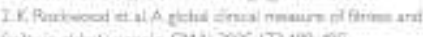

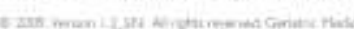
DALPOUSIE 
Figure 2. Participant Flow Diagram.

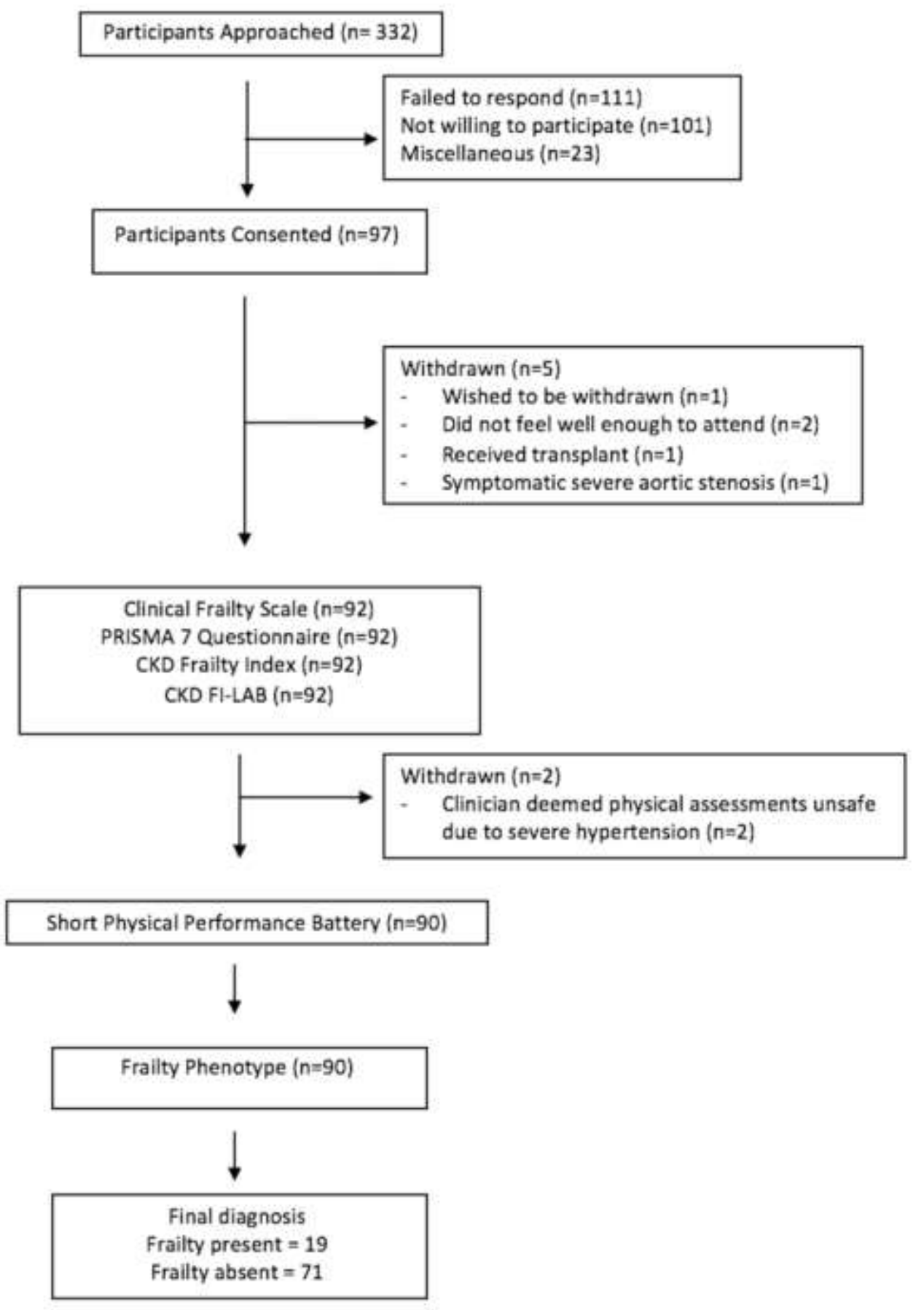


Figure 3. Prevalence of Robustness, Pre-Frailty and Frailty in CKD G4-5D Defined by the Frailty Phenotype.

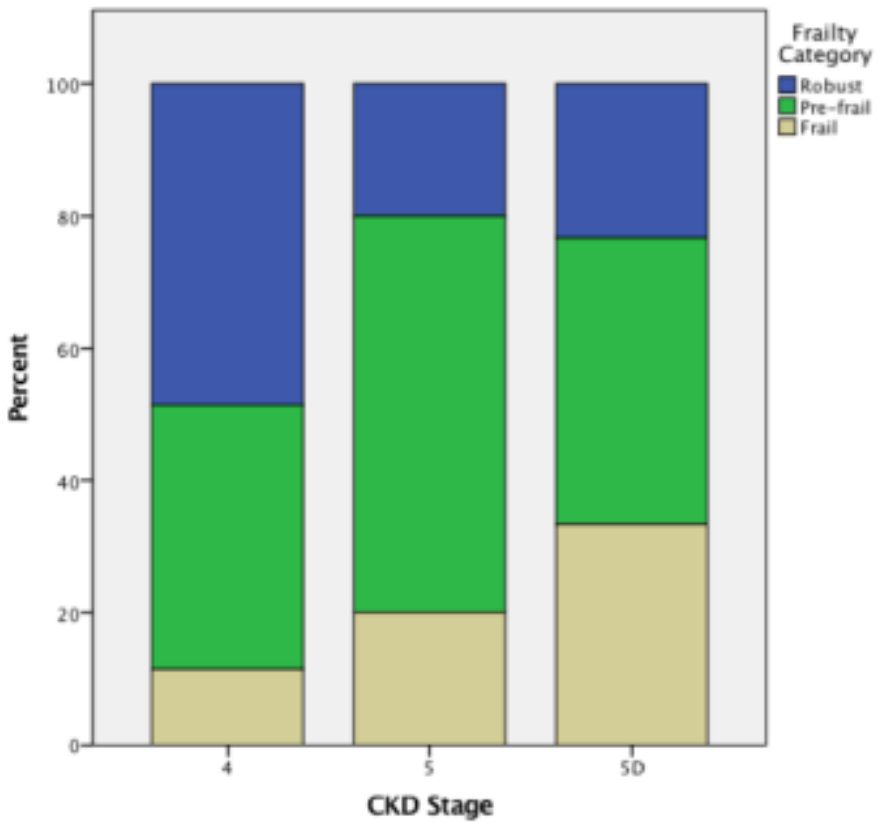

